\title{
Getting to Know SARS-CoV-2: Towards a Better Understanding of the Factors Influencing Transmission
}

\author{
Shadia Abdelhameed Elsayed 1,2(D), Osama Abu-Hammad1,3(D, Albraa B. Alolayan1@, Nebras

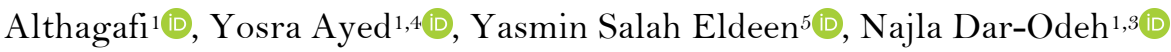

\begin{abstract}
${ }^{1}$ College of Dentistry, Taibah University, Al Madinah Al Munawarah, Saudi Arabia.
${ }^{2}$ Faculty of Dental Medicine for Girls, Al-Azhar University, Cairo, Egypt.

${ }^{3}$ School of Dentistry, University of Jordan, Amman, Jordan.

${ }^{4}$ Laboratory for Research on Biologically Compatible Compounds, Faculty of Dentistry, Monastir, Tunisia.

${ }^{5}$ Faculty of Pharmacy, Nahda University, Bani Sweif, Egypt.
\end{abstract}

Author to whom correspondence should be addressed: Shadia Abd-Elhameed Elsayed, Assistant Professor of Oral and Maxillofacial Surgery, College of Dentistry, Taibah University, KSA and Faculty of Dental Medicine for Girls, Al Azhar University, Cairo, Egypt. Phone: +966-541397891. E-mail: ssayed@,taibahu.edu.sa.

Academic Editor: Alessandro Leite Cavalcanti

Received: 06 June 2020 / Accepted: 22 June 2020 / Published: 30 June 2020

How to cite this article: Elsayed SA, Abu-Hammad O, Alolayan AB, Althagafi N, Ayed Y, Eldeen YS, et al. Getting to know SARS-CoV-2: towards a better understanding of the factors influencing transmission. Pesqui Bras Odontopediatria Clín Integr. 2020; 20(supp1):e0122. https://doi.org/10.1590/pboci.2020.123

\begin{abstract}
In November 2002, a virus known as SARS-CoV was identified in Guangdong, China, and it was implicated as the etiology of severe acute respiratory syndrome. Seventeen years later, in the same month of November, a similar disease with more dramatic outcomes was identified in neighboring Wuhan. It has been six months since the identification of first cases of COVID-19 pandemic; however, unveiling clinical characteristics and modes of transmission of the disease are taking longer than expected. This overview aims to highlight some important points regarding the mode of transmission for which continuously surprising facts are being revealed every day. We also raise some vital questions to alert the scientific community to find the right answers and minimize the drastic fatal outcomes of this disease. It can be stated that SARS-CoV-2 could be transmitted as aerosol infection as well as through contacting infected surfaces. The possible role of abdominal gases as a route of spread of the virus should be considered and a fecal sample might be a useful diagnostic tool. Moreover, medical face masks are not protective from virus transmission during treating COVID-19 patients in settings where aerosol-generating procedures are performed. Doffing of PPE for healthcare workers needs more attention as this might be a source of infection unless additional measures of PPE disinfection are employed before doffing.
\end{abstract}

Keywords: SARS Virus; Coronavirus Infections; Severe Acute Respiratory Syndrome. 


\section{Introduction}

It was November 2002 when a virus known as SARS-CoV was identified in Guangdong Province, China, and it was implicated as the etiological virus in severe acute respiratory syndrome (SARS). Seventeen years later, almost in the same month of November, a similar disease with more dramatic outcomes was identified in the neighboring Wuhan city. Coronaviruses are enveloped single-stranded large RNA viruses that infect both humans and animals. The name "corona” (crown in Latin) is attributed to the spherical shape of the core-shell and its surface projections resembling the solar corona. Four subfamilies of coronaviruses are identified; alpha-, beta-, gamma- and delta-coronaviruses [1]. It is thought that beta-coronaviruses originate from mammals, with bats being suspected due to similarity in the genome sequence of SARS-CoV-2, which is more than $90 \%$ similar to a Bat-CoV-RaTG13. In fact, a wide variety of coronaviruses are naturally occurring in bats, including SARS-CoV-like and MERS-CoV like viruses. The beta-coronaviruses are known to cause severe disease and fatalities.

Healthcare personnel should be experts in cross-infection control and barrier techniques. However, the multiple modes of COVID-19 transmission had been a continuous threat to the lives of all those working for care of COVID-19 patients. Some reports emerged from different countries indicating infection and even death of healthcare workers [2]. COVID-19 cases were estimated to be 8,944,481, while deaths were estimated to be 467,282 affecting more than 213 countries worldwide (last updated 21-6-2020, 11.21 GMT) [3].

WHO launched hundreds of free training courses to support millions on its different platforms through Health Emergencies Program, United Nations Crisis Management Team (UN CMT), Regional Updates, COVID-19 web page and daily reports web page. More facts about COVID-19 transmission and effective preventive measures should be revealed and disseminated among the medical community to preserve the precious lives of healthcare team members [4]. WHO released recently on 4 March 2020 a worldwide Surveillance Protocol among health care workers (HCW) and its aim was to identify the most appropriate infection control prevention measures to protect HCW [5].

In this critical review, we refer to the most recent update on modes of transmission of SARS-CoV-2 and the evidence base for effective cross-infection control measures in the clinical settings. We also raise some vital questions that the scientific community should tackle to find the right answers and minimize the drastic fatal outcomes of this disease.

\section{Modes of Transmission and Clinical Manifestations}

Modes of transmission of the virus can be described as being various. Close or direct contact with infected secretions or respiratory droplets produced by coughing, sneezing or talking, represent the major transmission route. Other modes of transmission include touching surfaces contaminated with the virus and touching mouth/nose/eyes [6].

Pneumonia was the initial clinical manifestation of COVID-19, which led to a description of this disease as an acute respiratory infection. So in the first instance, this disease was looked at as a respiratory infection, which only causes pulmonary manifestations. More recent reports also describe asymptomatic infections, neurological, and gastrointestinal symptoms. It is estimated that the majority of individuals infected by SARS-CoV-2 (80\%) remain asymptomatic throughout infection. In symptomatic patients, after an incubation period of less than one week on average, infection is manifested as fever, fatigue, dyspnea, and myalgia, which later progresses to pneumonia in the second or third week of infection. There will be reduced 
oxygen saturation, and chest radiographic pathology manifested as ground-glass abnormalities, patchy consolidation, alveolar exudates and interlobular involvement. On the other hand, the pediatric population is influenced less severely than adults by SARS-CoV-2, wherein $2 \%$ only of the affected patients are younger than 19 years [7]. Similar to adults, few children may be asymptomatic carriers; however, the most common clinical manifestations include fever and cough with less frequent manifestations, including typical manifestations of viral infection (fatigue, myalgia, headache, dizziness), respiratory virus infections (nasal congestion, runny nose, sneezing, sore throat), and gastrointestinal manifestations (vomiting, and abdominal pain) [8].

Moreover, SARS-CoV-2 appears to induce a late phase hyper-inflammatory syndrome similar to Kawasaki disease (mucocutaneous lymph node syndrome), which is a multisystem disorder characterized by fever and vasculitis. Studies that reported this association in children described the following manifestations of mucocutaneous involvement: cracked lip, skin rash, conjunctivitis and edematous hands and feet [9].

The extrapulmonary symptoms of the disease are now well recognized with the involvement of the liver, kidney, and even multisystem organ failure and acute cardiac arrest, which lead to sudden death of people, some of them were unfortunately spotted dying in the streets [10,11]. Approximately $50 \%$ of patients present with liver abnormalities in the form of elevated liver enzymes; however, the exact etiology of liver damage could be either due to COVID-19 infection or an adverse effect of antiviral drugs used for treatment [12]. Furthermore, it was noticed that the functional receptor of SARS-CoV-2, angiotensin-converting enzyme 2 (ACE2), is highly expressed in the bile duct's epithelial cells compared to hepatocytes or other interstitial cells [13].

Of special interest are the orofacial manifestations of the disease. Loss of smell and taste was reported in an Italian study where it was noticed that a substantial proportion of COVID-19 patients had lost taste and/or smell [14]. It is thought that the high availability of the virus in saliva [15] and its interaction with $\mathrm{ACE} 2$ receptor, which is widely expressed in the brain and oral mucosa (particularly the tongue) [16], are responsible for these manifestations. More recently, two case series were reported from Spain and France to explain the possible association between COVID-19 and oral ulcerations [17,18]. In these reports, some patients were not confirmed cases of COVID-19, and no investigations were done to exclude other viruses like the Herpes viruses, which are known to cause oral ulcers [19]. Therefore, the possibility that oral ulcers affecting patients in these reports are coincidental findings and that they were caused by another virus is valid.

The disease's gastrointestinal symptoms represent an important and interesting type of extrapulmonary symptoms, particularly when mode of transmission is concerned. While the mode of transmission of infection is respiratory, the fecal-oral route of transmission has now been identified and is suspected to be the mode of transmission in many studies [13]. The virus's nucleic acid has been detected in the feces of some COVID-19 patients indicating that live viruses are present in the feces and confirming that fecal-oral route of transmission is implicated [13]. ACE2 is known to be abundant in enterocytes (the intestinal lining epithelial cells) all over the small intestine including the duodenum, jejunum, and ileum, but were not detected in enterocytes of the colon or stomach [20]. Immunofluorescence showed that ACE2 was abundantly expressed in the glandular cells of the stomach, duodenum and rectum of infected patients [21]. It can thus be concluded that gastrointestinal cells of infected people do secret the virions [21]. Prevalence of diarrhea, nausea, vomiting, or abdominal discomfort is estimated to be approximately $5 \%$ [13].

Coronaviruses were mainly detected in fecal samples from bats but not in oral swabs, which implicates a predominantly gastrointestinal viral replication in bats [22]. The likely emergence of new coronaviruses from bats was already highlighted by scientists previously, and this was attributed to the fact that certain 
coronaviruses found in bats were able to infect humans without prior adaptation [23]. Based on this likely emergence, scientists warned against the lack of clinical data necessary for provision of effective treatment, which will compromise efforts to fight a pandemic when it arises [24].

These gastrointestinal symptoms precede respiratory symptoms in a substantial number of COVID-19 patients. Observations reported from clinicians caring for infected isolated patients, revealed expulsion of excess colonic gas, which has an unpleasant odor with or without diarrhea [25,26]. The intestinal gas content is mainly dependent on gas production by bacterial fermentation of unabsorbed substrates. Hence, it is plausible to say that the virus may modify the intestinal bacteria in COVID-19 patients through infection of the intestinal lining epithelium. Further, it was found that live SARS- CoV- 2 may exist in fecal specimens of patients with negative oropharyngeal specimens [27]. This indicates that viral infection of the gastrointestinal tract can persist longer way after virus is cleared from the respiratory tract [21]. Abdominal gases could be a route of spread of the virus that needs further investigations and a fecal sample might be a useful diagnostic tool. Other unusual recognized symptoms that may affect the gastrointestinal tract include loss of taste, which could also be accompanied by loss of smell [10,28].

\section{Factors Affecting the Viability of Virus}

Some advice of using hot drinks was thought to be sufficient to kill the virus in the pharynx; however, after that, this appeared not correct due to reports that said it could withstand up to $56^{\circ} \mathrm{C}$ degree $[11,25]$.

In the beginning, it was reported that virus is large in size and is not airborne spreading and it falls after 3 hours on grounds and surfaces. It is not an aerosol transmitted infection, so only infection control precautions and social distancing for at least one meter is enough to prevent the spread of the infection. Still, after a while, some researchers reported that it could be transmitted as an airborne infection that spread for more than 4 meters in the air [26].

Most human coronaviruses are transmitted by direct contact with infected secretions or by a respiratory mode of transmission. Bronchoalveolar lavage fluid samples and oral swabs were positive for SARS-CoV-2 using quantitative PCR and conventional PCR suggestive of a respiratory route. Stool samples may also be positive, and nosocomial spread is of main concern. Interpersonal transmission of SARS-CoV-2 occurs mainly between family members and close friends due to intimate contact with patients or asymptomatic carriers. Spread of SARS-CoV-2 through the respiratory tract, is achieved by droplets, respiratory secretions, and direct contact. The multiple possible routes of transmission could be explained by the fact that ACE2 receptor is abundantly present on epithelial cells of lung alveoli and enterocytes of small intestine. So far, clinical diagnosis of COVID-19 can be accurately achieved by identifying the viral nucleic acid in the nose, throat, or other respiratory tract using swab sampling followed by real-time PCR, further confirmed by next-generation sequencing.

\section{Effective PPE for SARS-CoV-2}

A total number of 425 infected cases were investigated demonstrating that the number of infected individuals may double every one week since each patient can spread infection to an average of 2.2 other individuals (Ro, or the expected number of secondary cases produced by a single (typical) infection in a completely susceptible population). This estimate is close to SARS-CoV, which caused an outbreak in 2003 and was associated with an Ro of 3 9. This indicates how serious is the transmission of COVID-19, which is classified as a high airborne consequence of infectious disease in the UK. 
Face masks are a primary type of personal protective equipment that protects the nose and mouth from spread of respiratory infections, making it and effective method to prevent transmission of respiratory microorganisms [29].

Recommendations of mandatory face masks use by symptomatic patients and healthcare workers were consistent since the outset of the pandemic; however, there was some controversy over their use in the general public and community settings. It was noticed that the advice of the US Surgeon General was against the use of face masks by healthy people. This was mainly due to two reasons; to discourage consumption of face masks, and preserve the limited supplies which are much needed for healthcare professionals, and also it was argued that face masks provide no effective protection against coronavirus infection. Recommendations from the UK and Germany are based on the scarcity of the evidence that supports the role of face masks in providing effective protection against respiratory infections in the public setting [30]. On the other hand, healthcare workers are largely dependent on face masks as part of droplet precautions when caring for patients with respiratory infections. At this time, it is recommended that vulnerable individuals stay safe by avoiding crowds and using surgical face masks rationally when exposed to high-risk area.

Indeed, COVID-19 could be transmitted from asymptomatic carriers; thus, it would be wise to reduce community transmission if everyone, including asymptomatic carriers, wears face masks. It is also important to note that face masks should be used appropriately, with the replacement of disposable masks, to maintain the protective effect of these masks. People in quarantine should wear face masks if they need to leave home for any reason, since some of them may be asymptomatic carriers who can pose a threat to others. Vulnerable populations of older adults and medically compromised patients are at particular risk and those should wear face masks if available. After easing lockdown, many countries now have announced that wearing face masks is mandatory [29].

Regular medical masks appeared to be enough at the beginning to prevent Coronavirus cross-infection among HCWs. Medical health workers who depend on this type only during treatment of COVID-19 patients are susceptible to infection and hence we saw a large number of medical staff infected by the virus in different countries like Egypt, Italy, and USA. These types of masks alone without a complete face shield are not adequate with active coronavirus [30,31]. WHO launched updated guidelines concerning effectiveness and advice in mask use on 5 June 2020, which developed by guidance development group (COVID-19 IPC GDG), and concluded from various systematic reviews that the use of N95 Respirator is more protective against Aerosol Generating Procedures (AGP) during setting for treating COVID-19 patients? Medical masks should be used continuously combined with face shields to avoid risk of transmission from splashes or droplets to the eyes during healthcare shift of treating symptomatic COVID-19 patients in other non-AGPs [32].

It is important to address the different aspects of face masks that need further research like duration of effectiveness of fabric or cloth masks, the measures to increase the effectiveness of disposable masks, and the invention of reusable masks [32]. Donning and doffing of PPE strictly following correct sequence does not guarantee coronavirus prevention, the mask is the last removed PPE. To prevent transmission from contaminated parts, it is recommended that PPE undergo disinfection in a special room assigned for disposal of used PPE.

\section{Conclusion}

This overview was conducted about mode of transmission of pandemic coronavirus (COVID-19) crisis, which still has surprising facts every day. Coronavirus could be transmitted as aerosol infection and not only 
through contact infected surfaces. Abdominal gases could be a route of spread of the virus and a fecal sample might be a useful diagnostic tool. Medical face masks are not protective from coronavirus during treating COVID-19 patients in a setting where aerosol-generating procedures are performed. There is a lack of evidence that fabric or cloth masks are protective for healthcare workers. Doffing of PPE for healthcare workers needs more attention as this might be a source of infection unless extra methods of disinfection of PPE before doffing are implicated.

\section{Authors' Contributions}

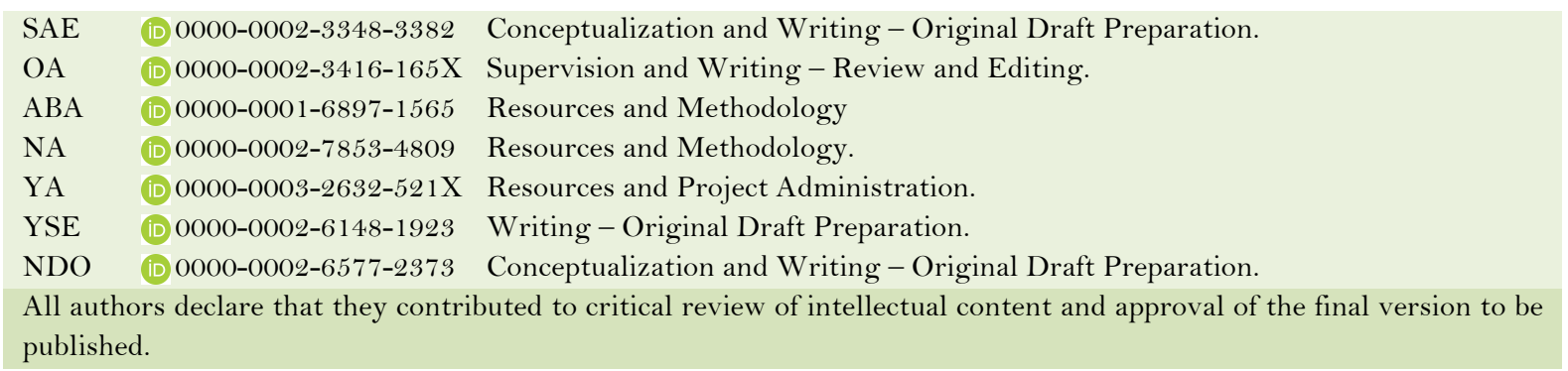

\section{Financial Support}

None.

\section{Conflict of Interest}

The authors declare no conflicts of interest.

\section{References}

[1] Zuckerman AJ, Banatvala JE, Schoub BD, Griffiths PD, Mortimer P. Principles and Practice of Clinical Virology: 6th Edition. London: Wiley-Blackwell; 2009.

[2] Zhan M, Qin Y, Xue X, Zhu S. Death from Covid-19 of 23 health care workers in China. N Engl J Med 2020; 382(23):2267-8. https://doi.org/10.1056/nejmc2005696.

[3] COVID-19 Coronavirus Pandemic. Avalilable from: https://www.worldometers.info/coronavirus. [Accessed on June $18,2020]$.

[4] World Health Organization. /publications/overview. Weekly update on COVID-19 - 5 June 2020. Available from: https://www.who.int/publications/m/item/weekly-update-on-covid-30-may---5-june-2020. [Accessed on June 18, 2020].

[5] World Health Organization. Surveillance Protocol for SARS-CoV-2 infection Among Health Workers. Available from: https://www.who.int/publications/i/item/WHO-2019-nCoV-HCW_Surveillance_Protocol-2020.1. [Accessed on June 18, 2020].

[6] Centers for Disease Control and Prevention. Coronavirus Disease 2019 (COVID-19). Available from: https://www.cdc.gov/coronavirus/2019-ncov/prevent-getting-sick/how-covid-spreads.html. [Accessed on June 18, 2020].

[7] Zimmermann P, Curtis N. Coronavirus infections in children including COVID-19. Pediatr Infect Dis J 2020; 39(5):355-68. https://doi.org/10.1097/inf.0000000000002660

[8] She J, Liu L, Liu W. COVID-19 epidemic: disease characteristics in children. J Med Virol 2020; 92(7):747-54. https://doi.org/10.1002/jmv.25807

[9] Licciardi F, Pruccoli G, Denina M, Parodi E, Taglietto M, Rosati S, et al. SARS-CoV-2-induced kawasaki-like hyperinflammatory syndrome: a novel COVID phenotype in children. Pediatrics 2020; 2020:e20201711. https://doi.org/10.1542/peds.2020-1711

[10] Centers for Disease Control and Prevention. Coronavirus Disease 2019 (COVID-19). Symptoms of Coronavirus. 2020. Available from: https://www.cdc.gov/coronavirus/2019-ncov/symptoms-testing/symptoms.html. [Accessed on June 18, 2020].

[11] Newman T. Coronavirus myths explored. Available from: https://www.medicalnewstoday.com/articles/coronavirus-myths-explored. [Accessed on June 17, 2020]. 
[12] Chen N, Zhou M, Dong X, Qu J, Gong F, Han Y, et al. Epidemiological and clinical characteristics of 99 cases of 2019 novel coronavirus pneumonia in Wuhan, China: a descriptive study. Lancet 2020; 395(10223):507-13. https://doi.org/10.1016/So140-6736(20)30211-7

[13] Li LY, Wu W, Chen S, Gu JW, Li XL, Song HJ, et al. Digestive system involvement of novel coronavirus infection: prevention and control infection from a gastroenterology perspective. J Dig Dis 2020; 21(4):199-204. https://doi.org/10.1111/1751-2980.12862

[14] Giacomelli A, Pezzati L, Conti F, Bernacchia D, Siano M, Oreni L, et al. Self-reported olfactory and taste disorders in SARS-CoV-2 patients: a cross-sectional study. Clin Infect Dis 2020; 2020:ciaa330. https://doi.org/10.1093/cid/ciaa330

[15] Kotfis K, Skonieczna-Żydecka K. COVID-19: gastrointestinal symptoms and potential sources of 2019-nCoV transmission. Anaesthesiol Intensive Ther 2020; 40157. https://doi.org/10.5114/ait.2020.93867

[16] Xu H, Zhong L, Deng J, Peng J, Dan H, Zeng X, et al. High expression of ACE2 receptor of 2019-nCoV on the epithelial cells of oral mucosa. Int J Oral Sci 2020; 12(1):8. https://doi.org/10.1038/s41368-020-0074-x

[17] Chaux-Bodard AG; Deneuve S, Desoutter A. Oral manifestation of Covid-19 as an inaugural symptom? J Oral Med Oral Surg 2020; 26:18. https://doi.org/10.1051/mbcb/2020011

[18] Carreras-Presas CM, Sánchez JA, López-Sánhez AF, Jané-Salas E, Pérez MLS. Oral vesiculobullous lesions associated with SARS-CoV-2 infection. Oral Dis 2020; 10.1111/odi.13382. https://doi.org/10.1111/odi.13382

[19] Abu-Hammad S, Dar-Odeh N, Abu-Hammad O. SARS-CoV-2 and oral ulcers: a causative agent or a predisposing factor? Oral Dis 2020. https://doi.org/10.1111/odi.13498

[20] Hamming I, Timens W, Bulthuis MLC, Lely AT, Navis GJ, van Goor H. Tissue distribution of ACE2 protein, the functional receptor for SARS coronavirus. A first step in understanding SARS pathogenesis. J Pathol 2004; 203(2):631-7. https://doi.org/10.1002/path.1570

[21] Cipriano M, Ruberti E, Giacalone A. Gastrointestinal infection could be new focus for coronavirus diagnosis. Cureus 2020; 12(3):e7422. https://doi.org/10.7759/cureus.7422

[22] Lau SKP, Woo PCY, Li KSM, Huang Y, Tsoi HW, Wong BHL, et al. Severe acute respiratory syndrome coronavirus-like virus in Chinese horseshoe bats. Proc Natl Acad Sci U S A 2005; 102(39):14040-5. https://doi.org/10.1073/pnas.0506735102

[23] Menachery VD, Yount Jr BL, Debbink K, Agnihothram S, Gralinski LE, Plante JA, et al. A SARS-like cluster of circulating bat coronaviruses shows potential for human emergence. Nat Med 2015; 21(12):1508-13. https://doi.org/10.1038/nm.3985

[24] de Wit E, van Doremalen N, Falzarano D, Munster VJ. SARS and MERS: recent insights into emerging coronaviruses. Nat Rev Microbiol 2016; 14(8):523-34. https://doi.org/10.1038/nrmicro.2016.81

[25] Cascella M, Rajnik M, Cuomo A, Dulebohn SC, di Napoli R. Features, evaluation and treatment Coronavirus (COVID-19). Treasure Island: StatPearls Publishing; 2020.

[26] Lewis D. Is the coronavirus airborne? experts can't agree. Nature 2020; 580:(7802):175. https://doi.org/10.1038/d41586-020-00974-w

[27] Nouri-Vaskeh M, Alizadeh L. Fecal transmission in COVID-19: a potential shedding route. J Med Virol 2020; 10.1002/jmv.25816. https://doi.org/10.1002/jmv.25816

[28] Spinato G, Fabbris C, Polesel J, Cazzador D, Borsetto D, Hopkins C, et al. Alterations in smell or taste in mildly symptomatic outpatients with SARS-CoV-2 infection. JAMA 2020; 323(20):2089-90. https://doi.org/10.1001/jama.2020.6771

[29] Odeh ND, Babkair H, Abu-Hammad S, Borzangy S, Abu-Hammad A, Abu-Hammad O. COVID-19: present and future challenges for dental practice. Int J Environ Res Public Health 2020; 17(9):3151. https://doi.org/10.3390/ijerph 17093151

[30] Desai AN, Aronoff DM. Masks and Coronavirus disease 2019 (COVID-19). JAMA 2020. https://doi.org/10.1001/jama.2020.6437

[31] Radonovich Jr LJ, Simberkoff MS, Bessesen MT, Brown AC, Cummings DAT, Gaydos CA, et al. N95 respirators vs medical masks for preventing influenza among health care personnel: a randomized clinical trial. JAMA 2019; 322(9):824-33. https://doi.org/10.1001/jama.2019.11645

[32] World Health Organization. Advice on the use of masks in the context of COVID-19: interim guidance, 6 April 2020. Available from: https://apps.who.int/iris/handle/10665/331693. [Accessed on June 18, 2020]. 